\title{
RANCANGAN PENINGKATAN EFEKTIVITAS MANAJEMEN RISIKO OPERASIONAL DI DIVISI KREDIT PADA KEGIATAN PEMBIAYAAN KONSUMEN SEPEDA MOTOR PT XYZ
}

\author{
Tineke \\ Program Studi S2 MM Eksekutif Muda \\ Sekolah Tinggi Manajemen PPM
}

\begin{abstract}
Terbatasnya sumber dana formal yang mampu mengatasi kebutuhan kredit masyarakat lapisan bawah yang berpenghasilan rendah merupakan alasan pendorong berkembangnya perusahaan pembiayaan konsumen. Melalui sistem pembiayaan konsumen, masyarakat lapisan bawah berpenghasilan rendah dapat memenuhi kebutuhan hidup layak yang sesuai dengan tingkat kemampuannya. Sepeda motor adalah salah satu kontribusi pertumbuhan perusahaan pembiayaan konsumen tersebut.

Kemudahan dalam memperoleh pembiayaan untuk pembelian sepeda motor secara kredit menjadi salah satu penyebab peningkatan penjualan sepeda motor di Indonesia yang dapat menimbulkan potensi risiko bagi perusahaan pembiayaan, tidak terkecuali dengan PT XYZ. Dalam kurun waktu 2010 sampai tahun 2011 PT XYZ mengalami penurunan kualitas kesehatan khususnya dari sisi pembiayaan dimana terjadi peningkatan Non Performing Loan (NPL) dari tahun ke tahun.

Tujuan dari penelitian ini adalah untuk mengidentifikasi, menganalisa, merumuskan dan menyusun rencana implementasi peningkatan efektivitas manajemen risiko operasional di divisi kredit PT XYZ. Dalam penelitian ini pendekatan yang dilakukan dengan pendekatan kualitatif dan mengacu pada ISO 31000 tahun 2009.

Berdasarkan hasil analisa manajemen risiko operasional divisi kredit PT XYZ yang teridentifikasi dari penelitian ini memiliki 8 risiko, yang paling tinggi dari dampak dan kemungkinan yang terjadi ada 2 risiko, yaitu : turnover Direksi dan key employee dalam Divisi Kredit serta keterlambatan dalam penarikan data yang diperlukan untuk laporan reguler setiap bulan.
\end{abstract}

Keywords:

Operational Risk Management, Credit Division, ISO 31000 


\section{PENDAHULUAN}

\subsection{Latar Belakang}

Dalam kurun waktu 2010 sampai tahun 2011 PT XYZ mengalami penurunan kualitas kesehatan khususnya dari sisi pembiayaan dimana terjadi peningkatan Non Performing Loan (NPL) dari tahun ke tahun. Non Performing Loan (NPL) adalah kredit yang masuk ke dalam kualitas kredit kurang lancar, diragukan dan macet berdasarkan kriteria yang telah ditetapkan oleh Bank Indonesia (SE No. 7/3/DPNP). Dalam Tabel 1. di bawah ini terlihat, kredit macet yang dihadapi PT XYZ lebih tinggi dibandingkan dengan perusahaan pesaing lainnya yang bergerak di industri yang sama.

Tabel 1.

Umur Piutang

\begin{tabular}{|c|c|c|c|c|c|c|c|c|c|c|}
\hline \multirow{2}{*}{$\begin{array}{l}\text { Year } \\
2011\end{array}$} & \multicolumn{2}{|c|}{ Current } & \multicolumn{2}{|c|}{ Overdue 1-90 } & \multicolumn{2}{|c|}{ Overdue 91-120 } & \multicolumn{2}{|c|}{ Overdue $>120$} & \multirow{2}{*}{$\begin{array}{c}\text { Total } \\
\text { IDR bn }\end{array}$} & \multirow{2}{*}{$\begin{array}{c}\% \\
\text { Total } \\
\text { OD }\end{array}$} \\
\hline & IIDR bn & $\%$ & IDR bn & $\%$ & IDR bn & $\%$ & $\begin{array}{c}\text { IDR } \\
\text { bn }\end{array}$ & $\%$ & & \\
\hline Adira & 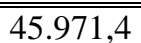 & 81,07 & 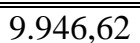 & 17,54 & 237,37 & $\overline{0,42}$ & $\overline{5552,52}$ & 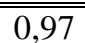 & "56.707,87 & 218,93 \\
\hline WOMF & $7.566,9$ & 77,47 & $1.989,88$ & 20,37 & 80,51 & 0,82 & 130,23 & 1,33 & $9.767,47$ & 22,53 \\
\hline
\end{tabular}

Sumber : PT XYZ, 2012 (diolah)

Salah satu faktor yang menyebabkan tingginya nilai NPL tersebut adalah adanya risiko pembiayaan yang muncul saat pemrosesan kredit, sangat penting untuk dikelola dalam rangka meningkatkan kualitas kredit yang pada akhirnya dapat meminimalkan kredit yang bermasalah. Pada tahun 2011, PT XYZ memiliki 1,180,460 konsumen di 228 cabang di seluruh Indonesia. Hal ini mengindikasikan potensi risiko kredit macet perusahaan pembiayaan ini menjadi semakin besar jika tidak dikelola dengan baik.

\subsection{Perumusan Masalah}

Berdasarkan uraian di atas, maka permasalahan penelitian dapat dirumuskan sebagai berikut, yaitu :

a. Apa saja risiko yang ada di Divisi Kredit PT XYZ yang ada saat ini ?

b. Apa penyempurnaan yang dibutuhkan untuk manajemen risiko di Divisi Kredit PT XYZ saat ini ?

c. Bagaimana langkah-langkah yang harus dilakukan agar penyempurnaan tersebut dapat dilakukan?

\subsection{Tujuan Penelitian}

Berdasarkan permasalahanpermasalahan yang ada maka tujuan dari penelitian ini adalah :

a. Mengidentifikasi risiko-risiko kredit yang ada di divis kredit PT XYZ.

b. Mengidentifikasi kebutuhan penyempurnaan manajemen risiko di divisi kredit PT XYZ saat ini.

c. Setelah kebutuhan penyempurnaan ditetapkan, kemudian dilanjutkan dengan pembuatan rekomendasi penyempurnaan bagi manajemen risiko kredit di PT XYZ.

\subsection{Batasan Penelitian}

Penyempurnaan sistem manajemen risiko di unit kredit ditujukan untuk PT XYZ, dengan prioritas penyempurnaan pada saat hasil (result based performance management). Contoh implementasi pada tesis ini dibatasi hanya pada salah satu unit kerja yaitu aktivitas dalam Divisi Kredit. Penelitian dilakukan dalam rentang waktu bulan Februari sampai dengan Mei 2013. Penelitian ini tidak memperhitungkan cost 
and benefit atas dijalaninya rekomendasi yang diberikan dengan pertimbangan keterbatasan waktu.

\section{TINJAUAN PUSTAKA}

\subsection{Pengertian Risiko}

Pengertian risiko menurut ISO

31000 tahun 2009, risiko adalah efek dari ketidakpastian dari suatu tujuan. Ketidakpastian tersebut termasuk kejadian yang mungkin atau tidak mungkin terjadi dan ketidakpastian karena dampak dari informasi yang tidak lengkap atau ambigu yang dapat berdampak pada tujuan yaitu dampak positif dan negatif.

\subsection{Proses Manajemen Risiko}

Proses manajemen risiko menurut Bramantyo Djohanputro (2012), dapat dilihat pada Gambar 1. sebagai berikut:

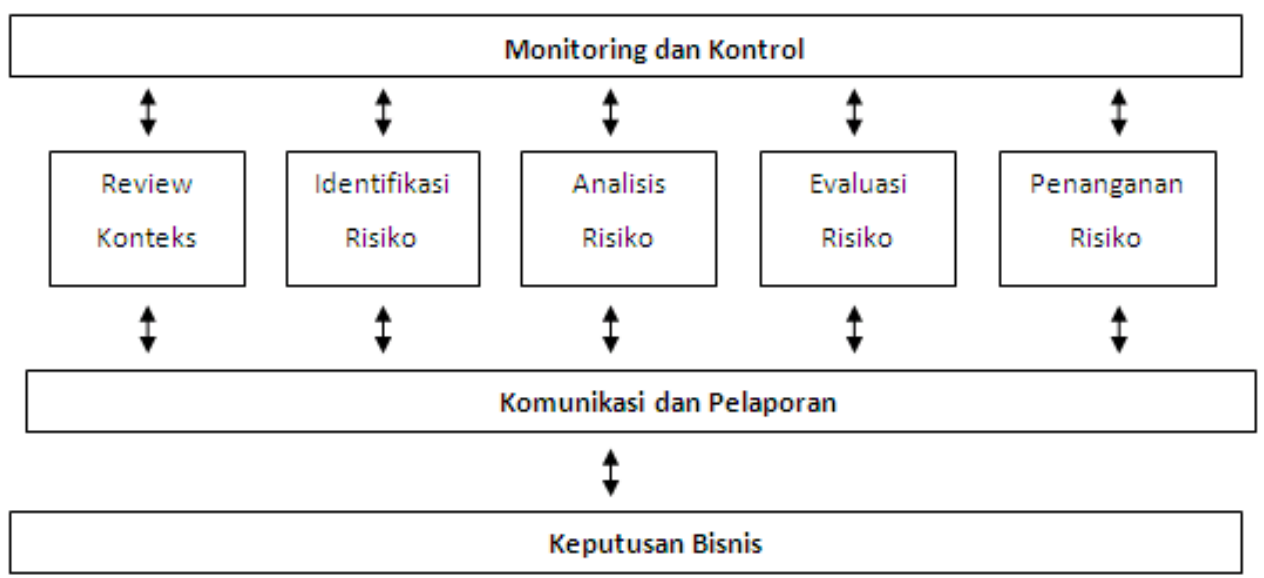

Gambar 1.

Proses Manajemen Risiko

a. Review Konteks (penetapan) kesiapan organisasi bertujuan untuk memastikan seberapa matang atau seberapa siap organisasi untuk menerapkan risiko, yaitu terdiri dari: kesiapan budaya risiko, kesiapan pimpinan puncak, kesiapan SDM, struktur organisasi.

b. Identifikasi risiko bertujuan untuk mengidentifikasi risiko yang harus dikelola organisasi melalui proses yang sistematis dan terstruktur. Pada tahapan ini terkait dengan memperoleh data (sumber data) dan klasifikasi risiko.

c. Analisa dan evaluasi risiko bertujuan untuk memahami proses pengukuran risiko berdasarkan dua dimensi utama ukuran risiko, memahami cara memetakan risiko untuk mengevaluasi status risiko dan menetapkan prioritas penanganan, dan mengetahui cara menetapkan posisi risiko dalam peta risiko terkait dengan preferensi risiko sehingga memahami hal-hal yang perlu dilakukan oleh organisasi terhadap masing-masing risiko.

d. Penanganan risiko bertujuan untuk memahami berbagai penanganan risiko untuk menghilangkan atau menurunkan status risiko yang dihadapi dan mengetahui mekanisme untuk 
memastikan proses manajemen risiko berjalan dengan produktif.

\subsection{Klasifikasi Risiko Operasional} Risiko operasional menurut Bramantyo Djohanputro (2012) terdiri dari :

a. Risiko produktivitas berkaitan dengan penyimpangan hasil atau tingkat produktivitas yang diharapkan karena adanya penyimpangan dari variabel yang mempengaruhi produktivitas kerja. Termasuk di dalamnya adalah teknologi, peralatan, material dan SDM.

b. Risiko teknologi berkaitan dengan potensi penyimpangan hasil karena teknologi yang digunakan tidak lagi sesuai dengan kondisi.

c. Risiko inovasi adalah potensi penyimpangan hasil oleh karena terjadinya pembaharuan, modernisasi, atau transformasi dalam beberapa aspek bisnis. Penyimpangan positif (perbaikan kinerja) terjadi apabila inovasi tersebut membantu proses operasi. Sebaliknya, inovasi beberapa aspek dapat menyebabkan terjadinya penyimpangan negatif apabila perusahaan tidak segera melakukan penyesuaian.

d. Risiko sistem adalah bagian dari risiko proses. Yaitu potensi penyimpangan hasil oleh karena adanya cacat atau ketidaksesuaian sistem dalam operasi perusahaan.

e. Risiko proses adalah risiko mengenai potensi penyimpangan dari hasil yang diharapkan dari proses oleh karena ada penyimpangan atau kesalahan dalam kombinasi sumber daya (SDM, keahlian, metode, peralatan, teknologi, dan material) dan karena perubahan lingkungan. Kesalahan prosedur merupakan salah satu bentuk perwujudan risiko proses.

\section{METODE PENELITIAN}

Dalam penelitian ini metode penelitian yang dipakai adalah heatmap, pemetaan probabilitas dan dampak.

\subsection{Metode Pengumpulan Data}

Metode yang digunakan untuk proses pengumpulan data dalam penelitian ini, yaitu:

a. Studi kepustakaan

Studi kepustakaan dilakukan dengan melakukan pencarian data di internet dan melalui buku-buku literature tentang manajemen risiko serta risiko kredit.

b. Analisa Internal dan Eksternal

Analisa internal dan eksternal dilakukan terhadap manajemen risiko $\mathrm{PT} \mathrm{XYZ}$ untuk mengetahui dan mengidentifikasikan risiko-risiko yang terdapat di dalam proses manajemen risiko kredit PT XYZ.

c. Analisa Data Historis

Metode yang mempergunakan berbagai informasi atau data mengenai segala sesuatu yang pernah terjadi.

\subsection{Penilaian Terhadap Risiko}

Dasar penentuan kemungkinan terjadinya risiko pada manajemen risiko di divisi kredit PT XYZ berdasarkan dari hasil pemeriksaan kejadian (audit) yang telah dilakukan. Probabilitas risiko menggunakan skala pengukuran skala ordinal dan dibagi dalam 5 kategori yaitu: jarang sekali, jarang, cukup sering, sering dan sangat sering seperti terlihat dalam Tabel 2 . berikut. 
Tabel 2.

Probabilitas Risiko

\begin{tabular}{|c||l||l||}
\hline Skala & \multicolumn{1}{|c|}{ Deskripsi } & \multicolumn{1}{c|}{ Frekuensi Kejadian } \\
\hline \hline 1 & Jarang Sekali (JS) & Historis dan pendapat ahli : sekali dalam 5 tahun \\
\hline \hline 2 & Jarang (J) & Historis dan pendapat ahli : paling banyak sekali dalam dua tahun \\
\hline \hline 3 & Cukup Sering (CS) & Historis dan pendapat ahli : paling banyak sekali dalam setahun \\
\hline 4 & Sering (S) & Historis dan pendapat ahli : paling banyak sekali dalam tiga bulan \\
\hline 5 & Sangat Sering (SS) & $\begin{array}{l}\text { Historis dan pendapat ahli : bisa terjadi lebih dari sekali dalam tiga } \\
\text { bulan. }\end{array}$ \\
\hline \hline
\end{tabular}

Dimensi berikutnya adalah dampak, yaitu tingkat kegawatan apabila risiko yang dihadapi benar-benar terjadi. Pada penelitian ini, dampak dibagi dalam 5 kategori yaitu: minor, moderate, severe, major, dan worse case dijelaskan pada Tabel 3. Berikut.

Tabel 3.

Dampak Risiko

\begin{tabular}{|c||l||l||}
\hline \multicolumn{1}{|c||}{ Skala } & \multicolumn{1}{|c|}{ Deskripsi } & \multicolumn{1}{c||}{ Keterangan } \\
\hline \hline 1 & Tidak Signifikan (TS) & Tidak tercapainya tujuan dalam skala dan cangkupan kecil. \\
\hline \hline 2 & Minor (MN) & $\begin{array}{l}\text { Tidak tercapainya tujuan organisasi, yang menyebabkan organisasi } \\
\text { terganggu dalam menjalankan proses kerja, namun gangguan terbatas } \\
\text { pada unit tertentu. }\end{array}$ \\
\hline \hline 3 & Moderat (MD) & $\begin{array}{l}\text { Tidak tercapainya tujuan organisasi sehingga organisasi perlu } \\
\text { memperbaiki proses kerja atau restruktur organisasi secara sederhana. }\end{array}$ \\
\hline \hline 5 & Katastropik (K) & $\begin{array}{l}\text { Tidak tercapainya tujuan organisasi sehingga organisasi perlu } \\
\text { memodifikasi strategi dan investasi besar. }\end{array}$ \\
\hline \hline
\end{tabular}

Dengan demikian dapat disusun peringkat risiko dan akan dibuat matriks

ancaman dan peluang seperti yang digambarkan pada Gambar 2.

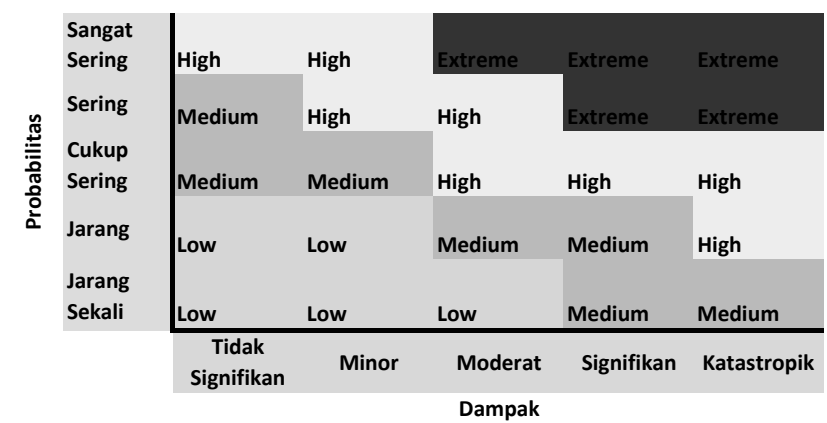

Gambar 2.

Matriks Ancaman dan Peluang 
IV. HASIL DAN PEMBAHASAN

\subsection{Identifikasi dan Analisa Risiko}

Berikut ini analisa risiko pada manajemen risiko di divisi kredit PT XYZ yang dikelompokan berdasarkan kejadian risikonya pada Tabel 4. Berikut.

Tabel 4.

Penilaian Risiko

\begin{tabular}{|c|c|c|c|c|c|c|}
\hline No & Kejadian Risiko & \multicolumn{2}{|c|}{ Probabilitas } & \multicolumn{2}{|c|}{ Dampak } & $\mathbf{P x D}$ \\
\hline 1 & $\begin{array}{l}\text { Kesalahan dalam menganalisa kelayakan calon konsumen } \\
\text { yang dibiayai. }\end{array}$ & $\mathrm{J}$ & 2 & $\mathrm{~S}$ & 4 & 8 \\
\hline 2 & $\begin{array}{l}\text { Turnover Direksi dan key employee dalam Divisi Kredit } \\
\text { terjadi setiap tahun. }\end{array}$ & SS & 5 & K & 5 & 25 \\
\hline 3 & $\begin{array}{l}\text { Telat dalam penarikan data yang diperlukan untuk laporan } \\
\text { reguler setiap bulan. }\end{array}$ & SS & 5 & K & 3 & 15 \\
\hline 4 & Adanya rangkap kerja. Proses kerja ada yang terlewatkan. & CS & 3 & $\mathrm{~S}$ & 4 & 12 \\
\hline 5 & Tindakan fraud yang dilakukan oleh karyawan. & $\mathrm{CS}$ & 3 & $\mathrm{MD}$ & 5 & 15 \\
\hline 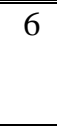 & $\begin{array}{l}\text { Tujuan kebijakan tidak tercapai, proses tidak dijalankan } \\
\text { dengan benar, kualitas portofolio yang tidak lancar } \\
\text { bertambah, laba perusahaan menurun. }\end{array}$ & 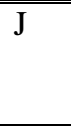 & 2 & S & 4 & 8 \\
\hline 7 & Kesalahan dalam pengambilan keputusan. & $\overline{\mathrm{J}}$ & 2 & $\mathrm{~K}$ & 5 & 10 \\
\hline 8 & $\begin{array}{l}\text { Ditemukan adanya dokumen fiktif, konsumen fiktif dan } \\
\text { kredit fiktif. }\end{array}$ & $\mathrm{S}$ & 4 & MN & 2 & 8 \\
\hline
\end{tabular}

Dari hasil penilaian risiko proses dan sistem IPEKA maka peneliti dapat sistem yang dapat dilihat pada Gambar 3 . memetakan penilaian risiko proses dan berikut.

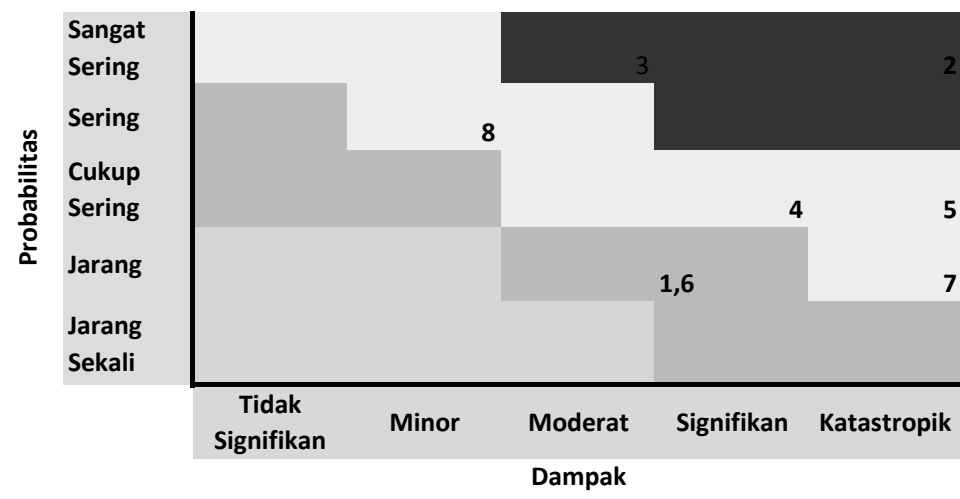

Gambar 3.

Pemetaan Penilaian Risiko

Dari Gambar 3. diperoleh tingkatan keutamaan untuk kejadian risiko di divisi kredit yang menjadi prioritas PT XYZ untuk ditangani, yaitu: 
a. Extreme

- Turnover Direksi dan key employee dalam Divisi Kredit terjadi setiap tahun.

- Telat dalam penarikan data yang diperlukan untuk laporan reguler setiap bulan.

\section{b. High}

- Kesalahan dalam pengambilan keputusan.

- Adanya rangkap kerja. Proses kerja ada yang terlewatkan.

- Tindakan fraud yang dilakukan oleh karyawan.

- Ditemukan adanya dokumen fiktif, konsumen fiktif dan kredit fiktif.

\section{c. Medium}

- Kesalahan dalam menganalisa kelayakan calon konsumen yang dibiayai.

- Tujuan kebijakan tidak tercapai, proses tidak dijalankan dengan benar, kualitas portofolio yang tidak lancar bertambah, laba perusahaan menurun.

\subsection{Penanganan Risiko}

Pada dasarnya penanganan risiko adalah usaha untuk mengurangi dampak risiko (impact) dan mengurangi kemungkinan risiko yang terjadi. Penangan risiko secara teknik dapat dilakukan dengan memetakan dalam kuadran-kuadran yang dapat digambarkan dalam Gambar 4. berikut.

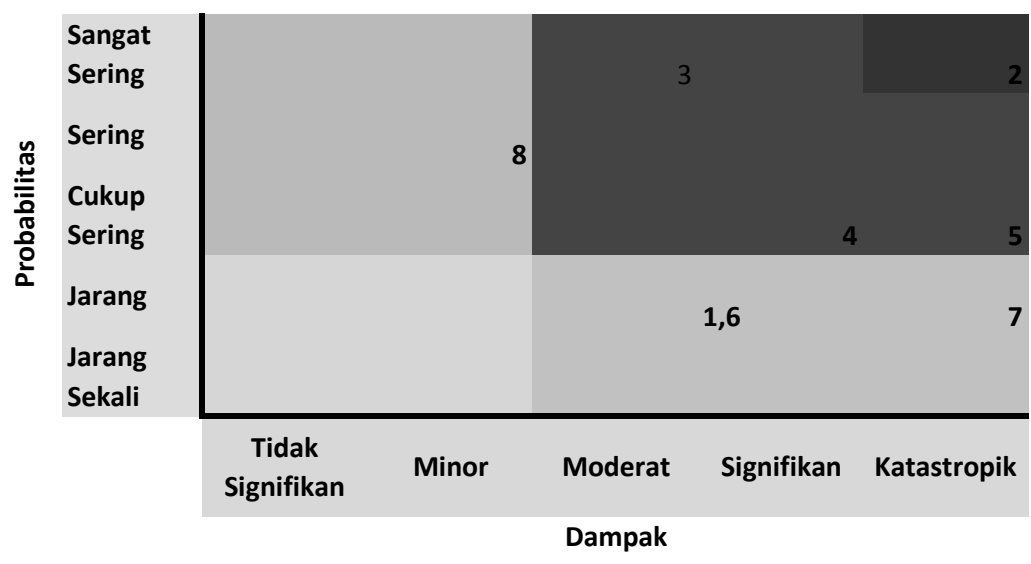

Gambar 4.

Kuadran Penanganan Risiko

a. Kuadran pertama (2)

- Penghindaran risiko (risk avoidance) adalah tindakan untuk tidak melakukan kegiatan tertentu yang mengandung risiko yang tidak diinginkan.

b. Kuadran kedua (1,6 dan 7)

- Pencegahan risiko (risk prevention) yaitu organisasi berusaha mengidentifikasi penyebab terjadinya dan kemudian mengambil tindakan supaya penyebab tersebut tidak terjadi.

- Pemindahan risiko (risk transfer) yaitu organisasi melakukan pemindahan sebagian dari risiko ke individu, entitas bisnis atau organisasi lain.

c. Kuadran ketiga (8)

- Pengurangan risiko (risk reduction) yaitu organisasi berupaya untuk mengurangi kemungkinan dan dampak 
dari risiko, pengurangan kerugian yang diakibatkan bila risiko tersebut terjadi, dan diversifikasi risiko.

d. Kuadran keempat (3,4 dan 5)

- Pencegahan risiko (risk prevention).

- Pengurangan risiko (risk reduction).

- Pemindahan risiko (risk transfer) e. Kuadran kelima

- Penerimaan risiko (risk acception) yaitu organisasi dapat menerima risiko, karena memang lebih ekonomis untuk menerima risiko tersebut.

Penanganan risiko pada manajemen risiko di divisi kredit PT XYZ dapat dilihat dalam tabel 5 . berikut.

Tabel 5.

Penanganan Risiko

\begin{tabular}{|c|c|c|c|c|c|}
\hline $\begin{array}{c}\text { Tingkat } \\
\text { Kepentingan }\end{array}$ & No & Jenis Risiko & $\begin{array}{c}\text { Jenis } \\
\text { Penanganan } \\
\text { Risiko }\end{array}$ & $\begin{array}{l}\text { Risiko Saat } \\
\text { Ini PXD }\end{array}$ & $\begin{array}{c}\text { Target } \\
\text { Risiko PXD }\end{array}$ \\
\hline \multirow{2}{*}{$\begin{array}{l}\text { Level } 1 \\
\text { Extreme }\end{array}$} & 2 & $\begin{array}{l}\text { Turnover Direksi dan key } \\
\text { employee dalam Divisi Kredit } \\
\text { terjadi selama tahun } 2011 .\end{array}$ & $\begin{array}{l}\text { Penghindaran } \\
\text { risiko }\end{array}$ & $5 \times 5$ & $2 \times 5$ \\
\hline & 3 & $\begin{array}{l}\text { Telat dalam penarikan data } \\
\text { yang diperlukan untuk laporan } \\
\text { reguler setiap bulan. }\end{array}$ & $\begin{array}{l}\text { Penghindaran } \\
\text { risiko }\end{array}$ & $5 \times 3$ & $2 \times 3$ \\
\hline \multirow{4}{*}{$\begin{array}{l}\text { Level } 2 \\
\text { High }\end{array}$} & 7 & $\begin{array}{l}\text { Kesalahan dalam pengambilan } \\
\text { keputusan. }\end{array}$ & $\begin{array}{l}\text { Pencegahan } \\
\text { risiko }\end{array}$ & $2 \times 5$ & $1 \times 5$ \\
\hline & 4 & $\begin{array}{l}\text { Adanya rangkap kerja. Proses } \\
\text { kerja ada yang terlewatkan. }\end{array}$ & $\begin{array}{l}\text { Pencegahan } \\
\text { risiko }\end{array}$ & $3 \times 4$ & $2 \times 4$ \\
\hline & 5 & $\begin{array}{l}\text { Tindakan fraud yang dilakukan } \\
\text { oleh karyawan. }\end{array}$ & $\begin{array}{l}\text { Pencegahan } \\
\text { risiko }\end{array}$ & $3 \times 5$ & 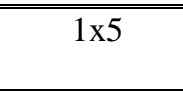 \\
\hline & 8 & $\begin{array}{l}\text { Ditemukan adanya dokumen } \\
\text { fiktif, konsumen fiktif dan } \\
\text { kredit fiktif. }\end{array}$ & $\begin{array}{l}\text { Pengurangan } \\
\text { risiko }\end{array}$ & $4 \times 2$ & $3 \times 2$ \\
\hline \multirow[b]{2}{*}{$\begin{array}{l}\text { Level } 3 \\
\text { Medium }\end{array}$} & 1 & $\begin{array}{l}\text { Kesalahan dalam menganalisa } \\
\text { kelayakan calon konsumen } \\
\text { yang dibiayai. }\end{array}$ & $\begin{array}{l}\text { Pemindahan } \\
\text { risiko }\end{array}$ & $2 \times 4$ & $1 \times 4$ \\
\hline & 6 & $\begin{array}{l}\text { Tujuan kebijakan tidak } \\
\text { tercapai, proses tidak } \\
\text { dijalankan dengan benar, } \\
\text { kualitas portofolio yang tidak } \\
\text { lancar bertambah, laba } \\
\text { perusahaan menurun. }\end{array}$ & $\begin{array}{l}\text { Pencegahan } \\
\text { risiko }\end{array}$ & $2 \times 4$ & $1 \times 4$ \\
\hline
\end{tabular}

Penanganan risiko difokuskan dan diutamakan pada risiko yang berada pada kuadran yang pertama dalam PT XYZ. Risiko-risiko tersebut adalah:

a. Turnover Direksi dan key employee dalam Divisi Kredit terjadi selama tahun 2011.
Penyebab kejadian risiko dikarenakan pengelolaan kredit dan struktur kompensasi tidak seimbang dengan produktifitas revenue. Sehingga rekomendasi yang diberikan adalah disusun target produktivitas/KPI yang harus dicapai disertai besaran insentif 
yang diberikan dari masing-masing menunjukkan bagaimana proses pencapaian target. Gambar $5 . \quad$ menyusun KPI.

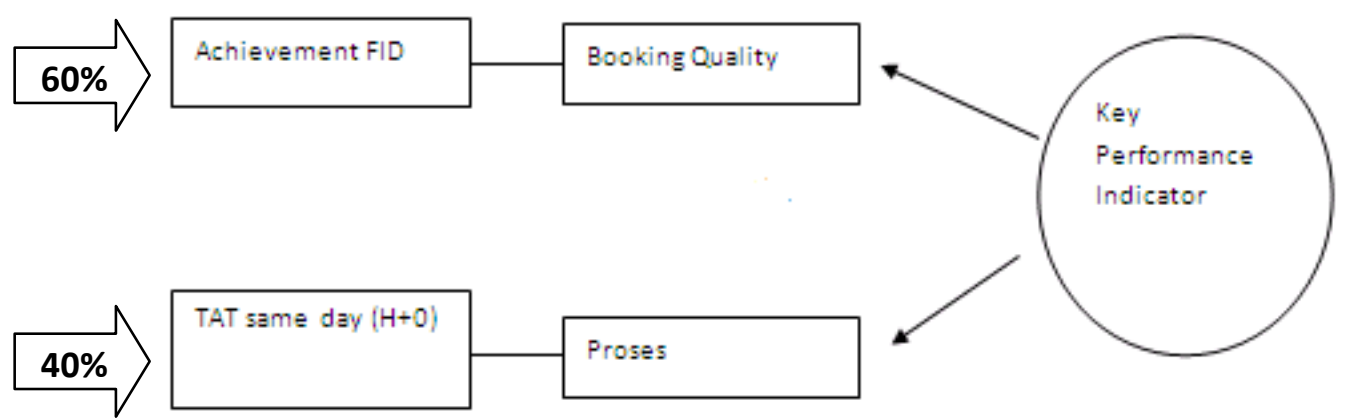

Gambar 5.

Proses Penyusunan KPI

- FID (First Installment Default)

Adalah \% unit (dibandingkan dengan kumulatif unit sales) dengan umur penjualan dari perhitungan cut off / closing bulan terakhir di posisi 2 sampai dengan 7 bulan dengan kondisi seperti pada Gambar 6.

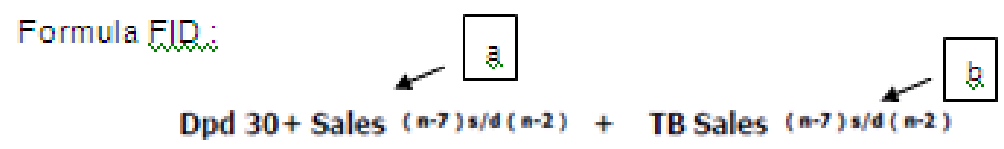

FID \%

Sales $(n-7) s / d(n-2) \sim 6$

Gambar 6.

FID

- Jumlah kumulatif unit yang pernah day past due di atas 30 hari atas total penjualan pada bulan cut off perhitungan dikurangi bulan ke-7 sampai dengan bulan cut off perhitungan dikurangi bulan ke-2.

- Jumlah kumulatif unit yang pernah Tarik Barang atas total penjualan pada bulan cut off perhitungan dikurangi bulan ke-7 sampai dengan bulan cut off perhitungan dikurangi bulan ke-2.

- Total unit penjualan atas total penjualan pada bulan cut off perhitungan dikurangi bulan ke-7 sampai dengan bulan cut off perhitungan dikurangi bulan ke-2.

- TAT (Turn Around Time) / Kecepatan Proses

Adalah kecepatan proses aplikasi dari mulai order diterima sampai dengan cetak PO (Purchase Order). Ada tiga kategori yaitu :

- TAT Approval : dari mulai order in sampai dengan cetak Purchase order.

- TAT Purchase Order : dari proses cetak PO sampai dengan Tagihan. 
- TAT Disbursement : dari proses tagihan sampai dengan SO.

Dari target KPI kredit tersebut disusunlah sasaran kinerja, dan bonus yang diberikan dari pencapaian target. Cara menghasilkan booking yang berkualitas adalah :

- Verifikasi yang handal akan membantu akurasi analisa kredit.
- Analisa yang akurat akan menghasilkan portofolio yang baik.

- Portofolio yang baik akan meminimalisasi kerugian.

- Potensi kerugian yang kecil akan memaksimalkan profit.

Rencana implementasi yang diberikan dapat dilihat pada Tabel 6.

Tabel 6.

Rencana Implementasi A

\begin{tabular}{|c|c|c|c|c|}
\hline Aktivitas & $\begin{array}{l}\text { Target } \\
\text { Waktu }\end{array}$ & Hasil & Yang Dilibatkan & $\begin{array}{c}\text { Yang } \\
\text { Menyetujui }\end{array}$ \\
\hline Penetapan besaran insentif & 2 minggu & $\begin{array}{l}\text { Besarnya insentif } \\
\text { yang diberikan }\end{array}$ & $\begin{array}{l}\text { Division Head Credit, } \\
\text { Manager Credit, HC. }\end{array}$ & Direktur \\
\hline $\begin{array}{l}\text { Dibuat IM ketentuan } \\
\text { besaran insentif berdasarkan } \\
\text { target yang telah ditetapkan }\end{array}$ & 1 minggu & $\begin{array}{l}\text { IM mengenai Key } \\
\text { Performance } \\
\text { Indicator dan } \\
\text { Insentif yang akan } \\
\text { diterima disertai } \\
\text { targetnya }\end{array}$ & Operation, Credit, HC & Direktur \\
\hline
\end{tabular}

b. Telat dalam penarikan data yang diperlukan untuk laporan reguler setiap bulan.

Penyebab kejadian risiko

dikarenakan Sistem Informasi Manajemen tidak akurat, tidak lengkap dan tidak tepat waktu.

Sistem Informasi Manajemen

berfungsi untuk mengumpulkan semua data dari semua pihak yang terkait dalam siklus perkreditan dan mengolah data untuk menjadi sumber informasi yang dapat dijadikan petunjuk peningkatan kinerja semua pihak yang terkait. Contohnya adalah bagian akuisisi kredit memerlukan informasi untuk mengetahui produktivitas tenaga kerja, persentase tingkat persetujuan (approval rate), tingkat penyimpangan (deviation rate), akurasi persetujuan. Sehingga rekomendasi yang diberikan adalah mencari vendor untuk mengembangkan sistem baru di IT, meeting internal divisi kredit memutuskan skala prioritas kebutuhan sistem yang mau didevelop. Pastikan agar sistem yang didevelop nanti dapat menjawab permasalahan dari sistem yang digunakan untuk keperluan divisi kredit sebelumnya.

Rencana Implementasinya dapat dilihat pada Tabel 7. 
Tabel 7.

Rencana Implementasi B

\begin{tabular}{|c|c|c|c|c|}
\hline Aktivitas & $\begin{array}{l}\text { Target } \\
\text { Waktu }\end{array}$ & Hasil & Yang Dilibatkan & $\begin{array}{c}\text { Yang } \\
\text { Menyetujui }\end{array}$ \\
\hline $\begin{array}{l}\text { Mengumpulkan Form dari } \\
\text { divisi kredit mengenai } \\
\text { sistem yang ingin didevelop }\end{array}$ & 1 bulan & $\begin{array}{l}\text { Perbaikan sistem } \\
\text { yang akan } \\
\text { didevelop }\end{array}$ & $\begin{array}{l}\text { Function Kredit, } \\
\text { khususnya Credit } \\
\text { Analyst }\end{array}$ & " Atasan terkait \\
\hline $\begin{array}{l}\text { Memilih perbaikan sistem } \\
\text { yang menjadi skala prioritas } \\
\text { pengerjaan }\end{array}$ & 1 minggu & $\begin{array}{l}\text { Daftar sistem yang } \\
\text { akan didevelop }\end{array}$ & Kredit dan IT & $\begin{array}{l}\text { Chief IT dan } \\
\text { BOD }\end{array}$ \\
\hline Aktivitas & $\begin{array}{l}\text { Target } \\
\text { Waktu }\end{array}$ & Hasil & Yang Dilibatkan & $\begin{array}{c}\text { Yang } \\
\text { Menyetujui }\end{array}$ \\
\hline $\begin{array}{l}\text { Mencari vendor untuk men- } \\
\text { develop sistem }\end{array}$ & 2 minggu & $\begin{array}{l}\text { Vendor yang akan } \\
\text { bekerjasama } \\
\text { dengan IT men- } \\
\text { develop sistem } \\
\text { yang baru }\end{array}$ & Kredit, IT & $\begin{array}{l}\text { Chief IT dan } \\
\text { BOD }\end{array}$ \\
\hline Pengembangan sistem & $\begin{array}{c}\text { Sesuai } \\
\text { kebutuhan } \\
\text { dan skala } \\
\text { kerumitan }\end{array}$ & Sistem yang baru & IT dan Vendor & IT, Kredit \\
\hline
\end{tabular}

\section{KESIMPULAN DAN SARAN}

\subsection{Kesimpulan}

Kesimpulan yang diperoleh dari penelitian ini adalah :

Risiko - risiko yang dihadapi dalam Divisi Kredit PT XYZ yang ada saat ini adalah :

a. Turn over karyawan dalam divisi Kredit.

b. Keterlambatan penarikan data yang diperlukan untuk laporan reguler setiap bulan.

c. Kesalahan dalam pengambilan keputusan.

d. Adanya rangkap kerja, proses kerja ada yang terlewatkan, ditemukan adanya dokumen fiktif dan kredit fiktif, kesalahan dalam menganalisa kelayakan calon konsumen yang dibiayai, dan adanya tindakan fraud yang dilakukan oleh karyawan.

e. Adanya tindakan fraud yang dilakukan oleh karyawan.
Penyempurnaan yang dibutuhkan untuk manajemen risiko dalam Divisi Kredit PT XYZ saat ini adalah melalui :

a. Penyusunan target produktivitas/ KPI disertai besaran insentif yang diberikan dari masing-masing pencapaian target.

b. Mencari vendor untuk mengembangkan sistem baru di IT.

Langkah-langkah yang harus dilakukan dapat dilihat dalam tabel rencana implementasi.

\subsection{Saran}

ini adalah :

Saran yang diberikan dari penelitian

a. PT XYZ membutuhkan sistem credit scoring yang sudah menggunakan data kolektif dari Kredit Biro.

b. Dalam penelitian selanjutnya agar cost and benefit yang dikeluarkan Perusahaan atas dijalankannya rekomendasi yang diberikan agar diperhitungkan.

c. Untuk penelitian selanjutnya agar menggali informasi apakah sudah ada 


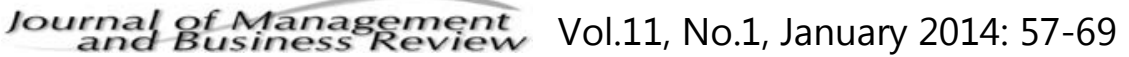

arahan dari PT Bank Internasional Indonesia Tbk sebagai induk perusahaan kepada PT XYZ dalam menjalankan manajemen risiko pada Divisi Kredit. 


\section{DAFTAR PUSTAKA}

APPI News edisi 42, 2011. Apresiasi APPI 2011 Multifinance. APPI. Jakarta.

Bank Indonesia. 2012. Kondisi Perusahaan Pembiayaan Tahun 2011 dalam Economic Review of Journal. http://www.google.com. [24 Mei 2012].

Departemen Keuangan Republik Indonesia. 2006. Ketentuan dan Tata Cara Pelaksanaan Lembaga

Pembiayaan melalui Keputusan Menteri Keuangan No. 84/PMK.012/2006.http://www.pajak.go.id.

Djohanputro, B. 2012. Manajemen Risiko Korporat Terintegrasi. Penerbit PPM. Jakarta

Kasmir.2004.Manajemen Perbankan. PT. Raja Grafindo Persada. Jakarta.

Susilo, L.J dan Victor Riwu Kaho. 2010. Manajemen Risiko Berbasis ISO 31000. Penerbit PPM. Jakarta. 